\title{
Green Open Access
}

Public Domain

\section{Source}

Open Research Glossary

Making a version of the manuscript freely available in a repository. 